\title{
Olor a Nenuco Estímulos químicos de cría y su impacto en la madre
}

\author{
Julia Antón Bergillos \\ al262483@uji.es \\ Pilar García Pardo \\ mapardo@uji.es \\ Manuela Barneo Muñoz \\ barneo@uji.es \\ Cinta Navarro Moreno \\ navarmor@uji.es \\ Fernando Martínez García \\ femartin@uji.es
}

\section{Resumen}

Una correcta conducta maternal es fundamental para la supervivencia de la descendencia y la maduración de su sistema nervioso. Esta investigación analiza el sustrato neuroendocrino de la conducta maternal en ratones, para ayudar a comprender la etiología de sus posibles alteraciones. El objetivo es entender por qué las madres muestran mayor motivación hacia las crías que las hembras vírgenes. Nuestra hipótesis plantea que, durante la gestación, factores endocrinos podrían estimular determinados centros del cerebro de las madres haciéndolos más sensibles a las feromonas de crías.

Para poner a prueba esta hipótesis hemos expuesto a madres y a hembras vírgenes a dos tipos de estímulo, crías y botones. Mediante la detección inmunohistoquímica de c-Fos medimos la actividad neuronal de sus centros quimiosensoriales (bulbos olfativos principal y accesorio, córtex piriforme, amígdala medial y cortical). El análisis estadístico (anova de dos factores, hembra y estímulo) no mostró diferencias significativas entre madres y comadres en la activación de los centros quimiosensoriales al exponerlas a crías o botones, aunque sí una tendencia a una mayor actividad en la amígdala medial posterodorsal en madres, independiente del estímulo. Finalmente, observamos una correlación significativa entre conducta maternal y actividad neuronal en centros quimiosensoriales en el grupo de hembras expuestas a crías, que sugieren el uso de circuitos neuronales diferentes entre madres y vírgenes durante su interacción con las crías. 
Palabras clave: feromonas, sistema olfativo, sistema vomeronasal, conducta maternal, motivación.

\begin{abstract}
Appropriate maternal behaviour is essential for offspring survival and for its neurodevelopment. This research analyses the neuroendocrine substrate of maternal behaviour in mice, to help understanding the aetiology of their possible disorders. Our goal is to understand why mothers show higher motivation towards offspring than virgin females. Our hypothesis postulates that changes induced by gestational hormones could sensitize specific mothers' brain centres to pup pheromones.

For this purpose, we exposed dams and virgin females to two different stimuli, pups and buttons. Through immunohistochemical detention of c-Fos, we assessed the neuronal activity in their chemosensory centres (main and accessory olfactory bulbs, piriform cortex, medial and cortical amygdala). A twoway ANOVA, with female and stimulus as factors, did not show differences between dams or virgins in the activation of chemosensory centres when exposed to pups or buttons, although it showed a nearly significant trend towards higher activation of the medial amygdala in dams, irrespective of the stimulus. Finally, we observed significant correlations between maternal behaviour and the activity of chemosensory centres in the group of females exposed to pups, which suggest the use of different neuronal circuits by dams and virgin females during their interaction with pups.
\end{abstract}

Keywords: pheromones, olfactory system, vomeronasal system, maternal behaviour, motivation.

\title{
Introducción
}

La conducta maternal está formada por una serie de comportamientos llevados a cabo por hembras, dirigidos a garantizar la supervivencia de las crías hasta su edad reproductiva, favoreciendo así el éxito reproductivo (Numan e Insel 2003). Además, la conducta maternal favorece el desarrollo del sistema nervioso de la progenie, por lo que supone un factor crítico para la salud tanto física como mental de la descendencia (Gammie 2005). Nuestro laboratorio analiza el sustrato neuroendocrino de la conducta maternal con el fin de entender la etiología de las distintas alteraciones relacionadas con esta, como el abandono infantil o la depresión postparto.

Para analizar este asunto utilizamos una aproximación experimental, siendo nuestro modelo el ratón. Dado que todos los vertebrados presentan un cerebro sociosexual muy conservado a lo largo de la evolución (Newman 1999), los roedores representan un buen modelo para el estudio de la neurobiología de las conductas sociales humanas, incluido el comportamiento maternal. Por otro lado, su corto período gestacional y la obtención de camadas numerosas lo convierten en una especie óptima para nuestro estudio en concreto (Navarro-Hernández 2012).

En los ratones, como en otros mamíferos, la conducta maternal puede dividirse en conductas dirigidas a las crías (recogida y agrupación de las crías en el nido, lactancia, termorregulación y aseo mediante el lameteo) y conductas no dirigidas a las crías (construcción del nido y defensa de este ante posibles amenazas, la llamada agresión maternal). Esta última ilustra bien las características de la conducta maternal, pues 
mientras las hembras de ratón se muestran amigables y pacíficas de forma natural con otros adultos, en el periodo perinatal se vuelven extremadamente agresivas hacia ellos (Martín-Sánchez 2016; Martín-Sánchez et al. 2015). Esto revela que la maternidad supone un cambio reversible en la conducta de las hembras dependiente de su periodo gestacional y, por tanto, posiblemente favorecido por las hormonas de la gestación.

Aunque tanto madres como hembras vírgenes de ratón son capaces de cuidar de las crías, existen dos facetas de la conducta maternal que únicamente se observan en las madres: la motivación hacia las crías y la ya comentada agresión maternal, desapareciendo ambas al final del período de lactancia. En este sentido, las hembras vírgenes y las madres muestran perfiles hormonales muy diferentes, lo que nos hace pensar que las hormonas de la gestación puedan provocar un cambio transitorio en el cerebro de las hembras: de cerebro sociosexual femenino a cerebro maternal. Esto es lo que denominamos maternización cerebral.

Los ratones utilizan estímulos químicos para la comunicación social, como las feromonas, sustancias químicas capaces de generar modificaciones en la conducta de otros animales de la misma especie (Karlson y Lüscher 1959). Por ello, nos preguntamos si la maternización puede ocurrir a nivel de los sistemas quimiosensoriales. A favor de esta hipótesis hay diversos estudios que demuestran la importancia de los sistemas quimiosensoriales en la conducta maternal. En uno de ellos (Wang y Storm 2011), se comparó la conducta maternal de madres con función olfativa normal y madres anósmicas (en las que se indujo una mutación nula de la adenilato ciclasa 3 , enzima clave para la transducción olfativa), observándose que las hembras anósmicas no mostraban conducta maternal.

En los roedores, la detección de estímulos químicos, entre ellos las feromonas, está mediada por dos órganos quimiosensoriales: el epitelio olfativo (OE) y el órgano vomeronasal (VNO) (Fortes-Marco, Lanuza y Martínez-García 2013). El primero está formado por neuronas ciliadas que tapizan el epitelio nasal, cuyos axones forman el nervio olfativo (par craneal 1a) que, a través de la placa cribosa del vómer, alcanzan los glomérulos del bulbo olfatorio principal (MOB). Se trata de un órgano que todos los vertebrados poseen (incluidos los seres humanos) y que forma el sistema olfativo principal. El segundo órgano quimiosensorial nasal, el órgano vomeronasal o de Jacobson, es un tubo ciego situado en el interior del hueso vómer, que se abre a la cavidad nasal. Está tapizado por un epitelio similar al olfativo, formado no obstante por neuronas sensoriales con microvellosidades que expresan receptores diferentes de los olfativos, cuyos axones forman el par craneal $1 \mathrm{~b}$ y acaban en los glomérulos del bulbo olfatorio accesorio (AOB). El término accesorio hace referencia al hecho de que no todos los vertebrados poseen este órgano, siendo la especie humana una de las que lo ha perdido (se encuentra en el embrión, pero se atrofia durante el final del desarrollo embrionario). Mientras que el órgano vomeronasal detecta fundamentalmente sustancias relacionadas con la comunicación social, incluyendo feromonas y otras señales químicas, al epitelio olfativo se le atribuye un papel genérico en la detección de olores de todo tipo, no solo sociales. Por lo tanto, en una especie macrosmática como el ratón, cabe esperar una implicación de ambos sistemas quimiosensoriales: olfativo principal y vomeronasal o accesorio, en la conducta maternal. Tal vez, en ratones, la detección de feromonas de las crías (olfativas, vomeronasales o ambas) desencadenaría en la madre una respuesta maternal instintiva, aún en ausencia de la estimulación hormonal apropiada, si bien esta potenciaría algunos aspectos de la conducta maternal como la motivación o la agresividad. El objetivo de nuestro estudio es contribuir a entender el papel de los estímulos olfativos y vomeronasales derivados de crías (o de otra naturaleza) en la conducta maternal en hembras lactantes y vírgenes. La hipótesis de trabajo general plantea que la maternización inducida por las 
hormonas durante la gestación podría incluir cambios en la expresión de receptores olfativos o vomeronasales, tal y como ocurre en machos (Tachikawa, Yoshihara y Kuroda 2013), que alterarían la sensibilidad a los estímulos químicos de crías, haciendo detectables feromonas de las mismas que inducirían un intenso comportamiento maternal motivado. Para poner a prueba nuestra hipótesis, planteamos los siguientes objetivos específicos:

- Buscaremos diferencias en la activación neuronal de los centros quimiosensoriales (olfativos y vomeronasales) de madres con respecto a hembras vírgenes, cuando son expuestas a estímulos de diferente naturaleza, crías y botones del mismo tamaño (estímulo control). La hipótesis de trabajo predice que puede haber un cambio en la sensibilidad de las madres hacia estímulos químicos de crías que estaría relacionado con los cambios en conducta.

- Igualmente buscaremos correlaciones entre la conducta maternal (calidad del cuidado de las crías) y la activación de los diferentes núcleos olfativos y vomeronasales, que explicarían la implicación de los estímulos químicos en la conducta maternal y podrían variar entre madres y hembras vírgenes.

- También buscaremos correlaciones significativas entre los núcleos implicados en la función quimiosensorial, lo que nos permitirá validar el método y comprobar la existencia de redes funcionales activadas en respuesta a estímulos de crías.

\section{Método}

\section{Diseño experimental}

Nuestro experimento incluyó 28 hembras de ratón de 10 semanas de edad, 14 madres y 14 comadres. Las comadres son hembras vírgenes que conviven con la madre y las crías durante el periodo de gestación, parto y lactancia. Si bien las comadres muestran una conducta maternal similar a la de las madres, no han sufrido la influencia de las hormonas de la gestación, por lo que son un buen control de la influencia endocrina responsable de la maternización cerebral. Dentro de cada subgrupo de hembras, expusimos la mitad a crías y la otra mitad a botones (como estímulo control). De esta forma, el diseño experimental contó con los 4 grupos experimentales que observamos a la derecha de la figura 1.

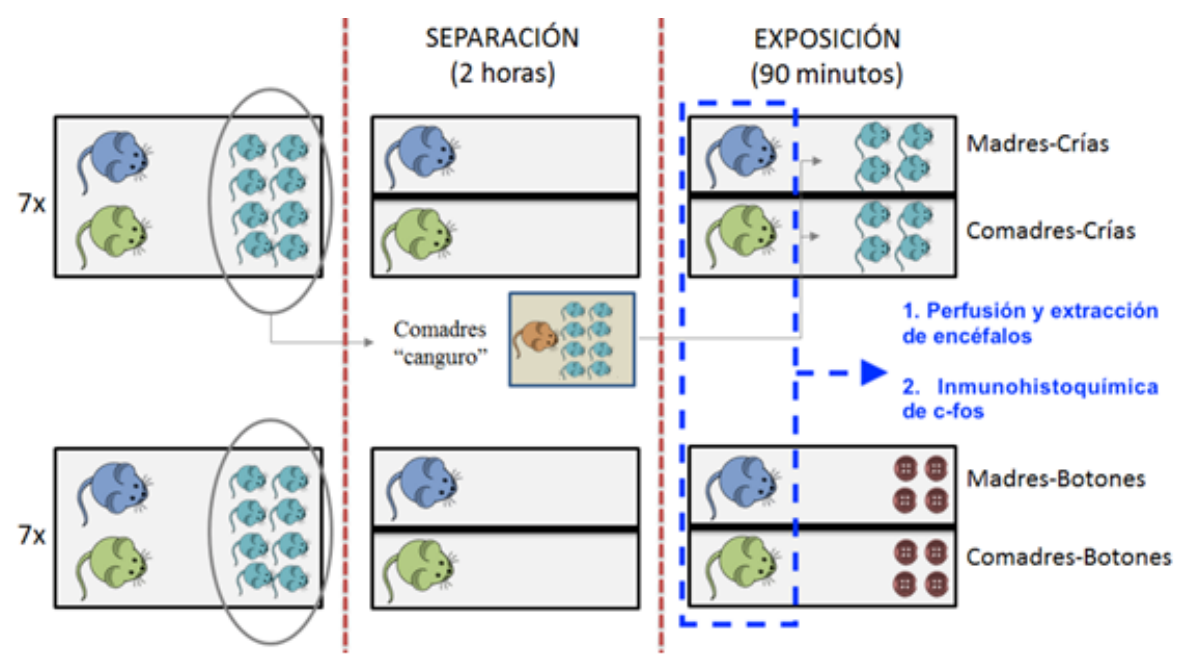

Figura 1. Muestra empleada y fases del estudio experimental (madres en azul, comadres en verde). 
Teniendo en cuenta que el cerebro responde a cambios en los estímulos, la presencia continuada de las crías no activará el cerebro por sí misma. Es necesario retirarlas durante un tiempo y después exponer a las hembras de nuevo a las crías, para asegurarnos de que el patrón de actividad cerebral que observaremos en los centros olfativos y vomeronasales es consecuencia de los estímulos químicos derivados de las mismas. Por ello, previamente a la exposición al estímulo, separamos las hembras de las crías durante 2 horas (véase la figura 1). Después procedimos a exponer a un primer grupo de hembras (madres y comadres) a las crías (reencuentro) y a un segundo al estímulo control (los botones). Tras 90 minutos de exposición, sacrificamos las hembras y les perfundimos fijador histológico. Una vez extraídos los encéfalos, los procesamos para la detección inmunohistoquímica de c-Fos (un factor de transcripción expresado por neuronas cuya expresión aumenta con la actividad eléctrica), que será nuestro marcador de actividad neuronal (Kovács 1998). En nuestro diseño experimental nos permitirá comprobar si hay diferencias de actividad neuronal en los centros quimiosensoriales del cerebro, en respuesta a crías o estímulos control (botones) entre madres y hembras vírgenes comadres.

\section{Análisis de la conducta maternal}

Realizamos el análisis de la conducta maternal a través de 7 vídeos de 90 minutos, correspondientes al período de exposición de las 7 parejas de hembras expuestas a crías. Solo analizamos estos grupos, puesto que las hembras expuestas a botones no pueden mostrar conducta maternal. Con el fin de reconocer de qué animal se trataba, previamente al experimento marcamos el pelaje de la comadre de cada pareja con henna. Las personas que analizaron los vídeos ignoraban este código y, por tanto, desconocían el tipo de hembra cuyo vídeo estaban evaluando. La medición de la conducta maternal consistió en asignar a cada intervalo de 10 segundos, durante 5 minutos, una puntuación de la calidad de la conducta maternal de acuerdo con la siguiente escala: 0 -hembra fuera del nido; 1 -hembra fuera del nido construyendo o manteniendo el nido; 2-hembra dentro del nido, pero no sobre las crías; 3-hembra sobre las crías; 4-aseo de las crías. Para cada animal se evaluaron así 30 episodios. Se promedió la puntuación de tres observadores diferentes y a cada animal se le asignó la puntuación media de todos los episodios.

\section{Procedimiento histológico}

El procedimiento histológico consistió en una inmunohistoquímica indirecta con avidina-biotina-peroxidasa para la detección de la proteína c-Fos. Usamos para ello el anticuerpo primario de la casa Synaptic Systems, obtenido en conejo y diluido 1:5000, seguido de un secundario biotinilado contra inmunoglobulinas de conejo obtenido en cabra a dilución 1:400 (Vector Labs) y el complejo avidina-biotina-peroxidasa de la misma casa. La peroxidasa resultante fue revelada con diaminobencidina (DAB) $0,025 \%$ y $\mathrm{H}_{2} \mathrm{O}_{2}$ al $0,01 \%$ en tampón, durante 20 minutos. La inmunotinción marcó el núcleo de las células activadas de color marrón. Para estimar el grado de actividad de cada centro nervioso medimos la densidad de células marcadas por unidad de área. Esta variable nos permitió hacer comparaciones entre los distintos grupos de animales (madres o comadres), expuestos a los distintos estímulos (crías o botones).

\section{Captación y análisis de imágenes}

Tras la inmunohistoquímica, captamos fotografías de las áreas cerebrales implicadas en la función quimiosensorial con una cámara (Leica AG. Alemania) conectada a un 
microscopio óptico Leitz DM 750. Del sistema olfativo, obtuvimos imágenes del bulbo olfatorio principal (MOB a 40x, capa granular) y de dos zonas del córtex piriforme (anterior, PirAnt; posterior, PirPost, ambas a 20x). Por otro lado, del sistema vomeronasal captamos imágenes del bulbo olfatorio accesorio (AOB a 40x, capa mitral) y de la amígdala cortical posteromedial (PMCo, a 20x). Además, también captamos un núcleo mixto (olfativo-vomeronasal), la amígdala medial (MePD, a 20x), que recibe aferencias tanto del MOB como del AOB. La cuantificación de la densidad de células marcadas en una determinada área se realizó mediante el programa ImageJ, que nos permitió binarizar la imagen captada y contar los núcleos de las células marcadas por encima de un determinado nivel de inmunotinción. A partir del número de células calculamos la densidad (células/10000 $\mu \mathrm{m} 2$ ).

\section{Análisis estadístico}

Para analizar los resultados obtenidos empleamos el programa IBM SPSS Statistics (versión 22). Por un lado, analizamos las posibles diferencias en la densidad de células marcadas por c-Fos en los 4 grupos diferentes de hembras. En primer lugar, realizamos pruebas para comprobar la normalidad de nuestros datos (KolmogorovSmirnov, ya que $n<50$ ), requisito necesario para poder utilizar un test paramétrico. Transformamos los datos que no mostraron una distribución normal (PMCo) en sus logaritmos para su análisis (dada la elevada variabilidad entre los datos, preferimos este método a un test no paramétrico). En segundo lugar, mediante el test de Levene comprobamos si existía homogeneidad de varianzas, segunda condición para la utilización del test estadístico paramétrico. Una vez comprobamos que se cumplían ambos requisitos, realizamos una ANOVA con dos factores: hembra (madre/comadre) y estímulo (crías/botones), lo que nos permitió evaluar las diferencias en la activación cerebral de cada grupo debidas a estos dos factores o a la interacción entre ambos. Una t de Student nos permitió comparar la puntuación de conducta maternal de las madres y las comadres. Como en estudios previos, las madres y las comadres mostraron conductas de cuidado de crías similares.

Por otro lado, comprobamos la existencia de correlaciones entre la conducta maternal medida en los vídeos y la activación de las diferentes áreas quimiosensoriales, así como la correlación entre todas estas áreas entre sí (resultados no mostrados). Este análisis únicamente lo realizamos en las madres y las comadres expuestas a crías (ya que los grupos expuestos a botones no muestran conducta maternal). La conducta maternal seguía una distribución normal, por lo que trabajamos con los valores originales; sin embargo, como PMCo no cumplía criterios de normalidad, decidimos transformar logarítmicamente los valores de densidad de c-Fos de todos los núcleos quimiosensoriales. Tras cerciorarnos de que todos nuestros datos seguían una distribución normal, realizamos test de correlación de Pearson (paramétrico) entre las diferentes variables, analizando los dos grupos de hembras (madres y comadres) por separado.

\section{Resultados}

\section{Diferencias en la densidad de c-Fos de los 4 grupos de hembras}

Los resultados de nuestro análisis mostraron que no hay diferencias estadísticamente significativas en la densidad de c-Fos entre los tipos de hembras, ni entre estímulos, ni existe una interacción entre ambos, ya que el p-valor quedó por encima de 0,05 en todos los casos. Sin embargo, sí que pudimos observar una tendencia hacia un resultado significativo en la amígdala medial posterodorsal en el tipo de hembra (F1, 
$24=3,914 ; p=0,059)$ que sugería un incremento de la actividad de este núcleo en las madres respecto de las comadres, y que parecía independiente del tipo de estímulo (igual para crías y botones; véase la figura 2).
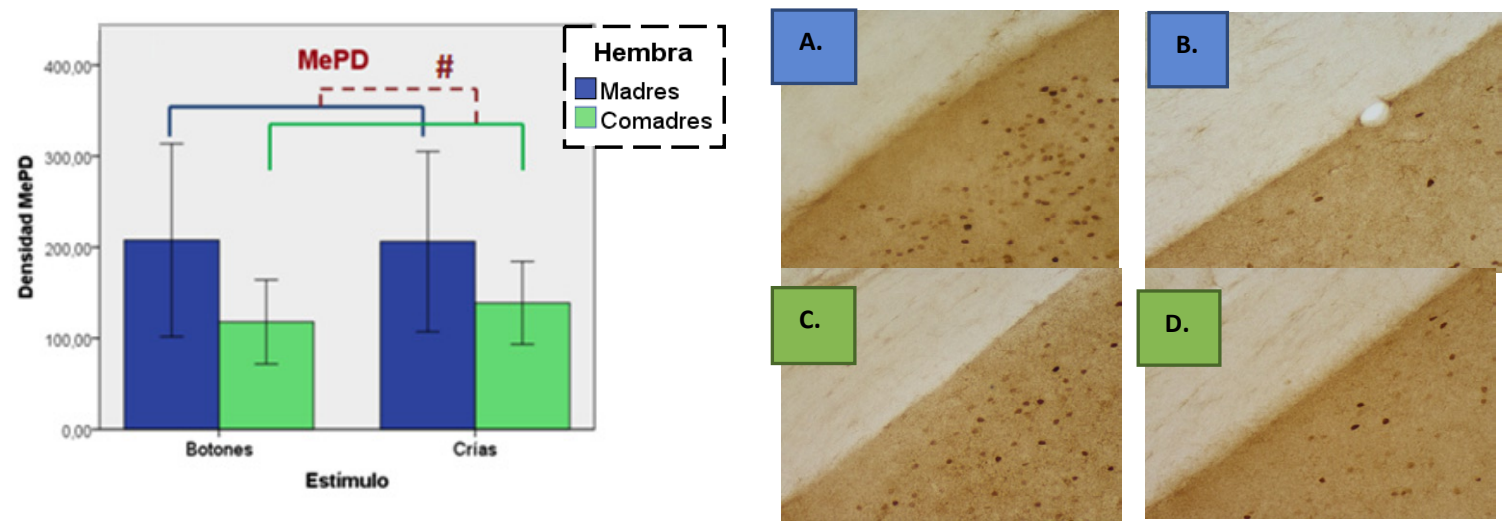

Figura 2. A la izquierda, gráficos de barras representativos de los resultados de las ANOVA de c-Fos para la amígdala medial (MePD). En el eje $Y$ se representa la densidad de células marcadas medida en células $/ \mathrm{mm}^{2}$ y en el eje de la $X$ los distintos grupos experimentales. A la derecha, una representación gráfica de las diferencias de densidad de células marcadas por c-Fos en los 4 grupos experimentales (A: madres expuestas a crías; B: madres expuestas a botones;

C: comadres expuestas a crías; D: comadres expuestas a botones).

Correlación entre la conducta maternal y la actividad de los núcleos quimiosensoriales en los grupos expuesto a crías.

Tabla 1

Análisis de correlación entre la conducta maternal y la actividad neuronal observada en los núcleos quimiosensoriales (densidad de células c-Fos positivas).

\begin{tabular}{|c|c|c|c|c|c|c|c|}
\hline & & LogAOB & LogMOB & LogPirAnt & LogPost & LogPMCo & LogMePD \\
\hline \multirow{2}{*}{$\begin{array}{l}\text { CONDUCTA } \\
\text { MADRES }\end{array}$} & $\begin{array}{c}\text { Correlación de } \\
\text { Pearson }\end{array}$ & 0,784 & $-0,637$ & $-0,647$ & $-0,269$ & $-0,544$ & 0,267 \\
\hline & $\begin{array}{c}\text { p-valor } \\
\mathrm{N}\end{array}$ & $\frac{0,065}{6}$ & $\begin{array}{c}0,124 \\
7\end{array}$ & $\begin{array}{c}0,116 \\
7\end{array}$ & $\begin{array}{c}0,559 \\
7\end{array}$ & $\begin{array}{c}0,264 \\
6\end{array}$ & $\begin{array}{c}0,562 \\
7\end{array}$ \\
\hline \multirow{3}{*}{$\begin{array}{l}\text { CONDUCTA } \\
\text { COMADRES }\end{array}$} & $\begin{array}{l}\text { Correlación de } \\
\text { Pearson }\end{array}$ & $-0,444$ & $-0,835^{*}$ & $-0,759^{*}$ & $-0,522$ & $-0,351$ & $-0,356$ \\
\hline & $\mathrm{p}$-valor & 0,377 & $\underline{0,039}$ & $\underline{0,048}$ & 0,229 & 0,44 & 0,433 \\
\hline & $\mathrm{N}$ & 6 & 6 & 7 & 7 & 7 & 7 \\
\hline
\end{tabular}

*. La correlación es significativa en el nivel 0,05 (2 colas).

Resultados significativos $(<0,05)$

Tendencias $(<0,1)$

En el grupo de las madres no se obtuvo ninguna correlación significativa entre la conducta maternal y la actividad en los núcleos quimiosensoriales (tabla 1), pero sí pudimos observar una tendencia $(p$-valor $=0,065$ ) hacia una correlación positiva $(R=0,784)$ entre la conducta y la actividad neuronal en el AOB. 
En cambio, en el grupo de comadres obtuvimos correlaciones negativas estadísticamente significativas (tabla 1); la primera, de la conducta maternal con la actividad del MOB $(R=-0,835$; $p$. valor $=0,039)$ y la segunda con la actividad del PirAnt $(R=-0,759$; $p$-valor $=0,048)$.

\section{Discusión}

Los resultados indican que, aparentemente, madres y comadres presentan una respuesta similar de los centros olfativos y vomeronasales a ambos estímulos (crías y botones). En cambio, la tendencia encontrada en la amígdala medial nos sugiere una mayor activación en madres respecto a comadres, aunque de forma indiferente al tipo de estímulo. La amígdala medial está relacionada con el cerebro sociosexual, que controla las conductas sociales instintivas, entre ellas la maternal. La activación que se observa en este núcleo podría deberse a que es un centro integrador de los diferentes estímulos quimiosensoriales, ya que recibe aferencias tanto de olfativo como de vomeronasal (Cádiz-Moretti, Otero-García, Martínez-García y Lanuza 2016).

Por otro lado, llama la atención la tendencia hacia la existencia de una correlación positiva en madres entre la conducta maternal y la actividad bulbo olfatorio accesorio, que no existe en comadres. Estos resultados sugieren una mayor implicación del sistema vomeronasal (del que el $A O B$ es el centro primario) en la conducta maternal en madres. En cambio, los resultados de las correlaciones negativas en comadres entre la conducta maternal y la actividad de dos núcleos del sistema olfativo sugieren el uso de la olfacción en conductas no relacionadas con el comportamiento maternal, como la exploración de la caja o el olfateo del entorno.

Todos estos resultados podrían estar indicándonos el uso de los sistemas quimiosensoriales de forma diferencial entre madres y comadres en la conducta maternal, fruto de una maternización del cerebro como resultado de la acción de las hormonas de la gestación, parto o lactancia (por ejemplo, la prolactina y los lactógenos placentarios) (Salais-López, Lanuza, Agustín-Pavón y Martínez-García 2017).

Con todo, podríamos deducir que la motivación aumentada hacia las crías en madres con respecto a hembras vírgenes no parece tener su origen en un gran cambio en la sensibilidad de las madres a estímulos químicos de cría. Cabe la posibilidad de que las madres sufran un pequeño cambio en la sensibilidad de algún receptor olfativo o VNO debido a las hormonas de la gestación. Si bien un cambio tan sutil es indetectable mediante la técnica de c-Fos aplicada a centros cerebrales, sí podría serlo si se estudiara la actividad del órgano vomeronasal o epitelio olfativo directamente. De hecho, en ratones, se ha comprobado un cambio similar en machos relacionado con la expresión de comportamiento paternal (Nakahara et al. 2016; Tachikawa, Yoshihara y Kuroda 2013), donde cambios en la sensibilidad de receptores olfativos atípicos expresados por neuronas vomeronasales se relacionan con la expresión de conducta paternal o infanticida.

La hipótesis que nuestros resultados generan, pese a no haber encontrado diferencias apreciables en la actividad de las áreas quimiosensoriales primarias ( $A O B$ y MOB) entre madres y comadres, es que pequeños cambios en la sensibilidad de algún (o algunos) receptor olfativo o vomeronasal de las madres, junto con la convergencia de estímulos olfativos y vomeronasales que se sumarían de forma no lineal en la amígdala medial (véase la figura 3), daría lugar a una mayor respuesta de este núcleo en las madres. De esta forma, al encontrarse este núcleo en estrecha relación con el cerebro sociosexual y, en consecuencia, relacionado con las conductas sociales 
instintivas (como la maternal), estos cambios podrían dar lugar a la conducta maternal motivada típica del período maternal.

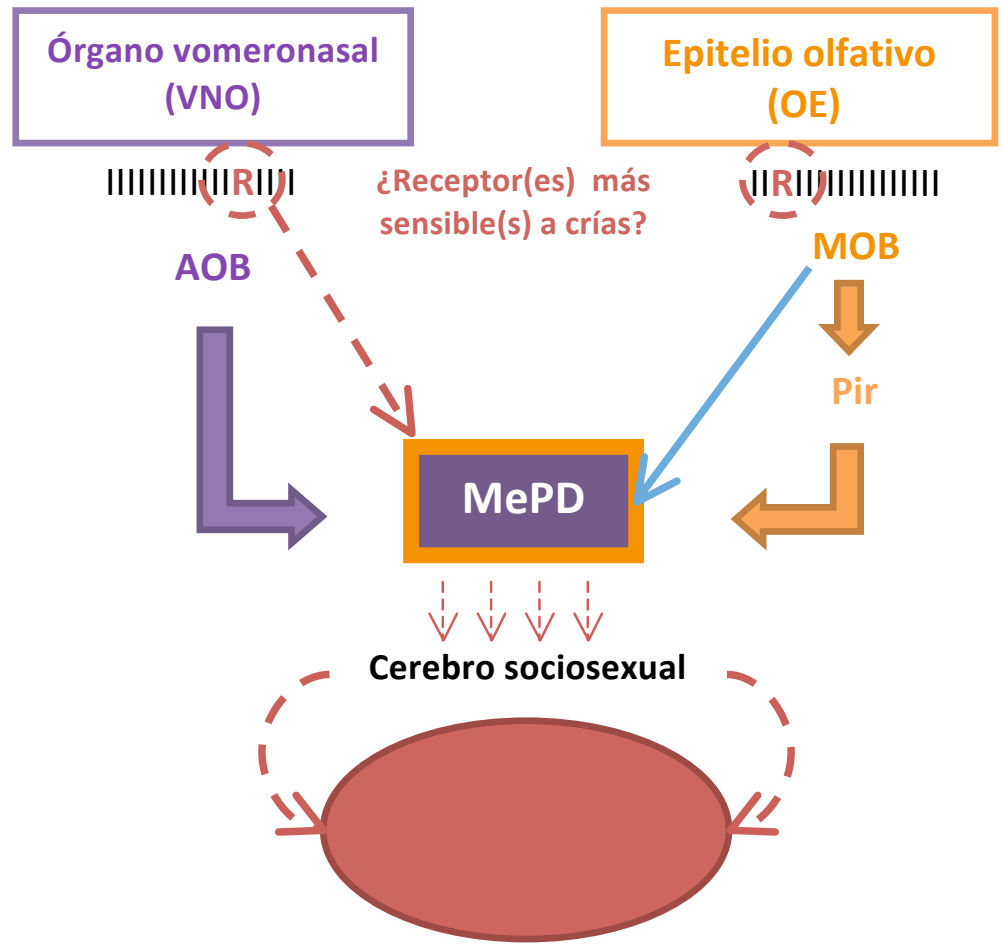

Figura 3. Esquema de conclusión, donde se representa la nueva hipótesis generada.

\section{Agradecimientos}

Este trabajo ha sido subvencionado con fondos del MINECO-FEDER (BFU201677691-C2-2-P y C2-1-P), de la Generalitat Valenciana (PROMETEO/2016/076) y de la Universitat Jaume I de Castelló (UJI-B2016-45).

\section{Referencias bibliográficas}

Cádiz-Moretti, Bernardita, Marcos Otero-García, Fernando Martínez-García y Enrique Lanuza. 2016. "Afferent projections to the different medial amygdala subdivisions: a retrograde tracing study in the mouse». Brain Structure and Function 221(2): 1033-1065. http://doi.org/10.1007/s00429-014-0954-y

Fortes-Marco, Lluís, Enrique Lanuza y Fernando Martínez-García. 2013. «Of pheromones and kairomones: What receptors mediate innate emotional responses?». Anatomical Record 296(9): 1346-1363. http://doi.org/10.1002/ar.22745

Gammie, Stephen C. 2005. "Current models and future directions for understanding the neural circuitries of maternal behaviors in rodents». Behavioral and Cognitive Neuroscience Reviews 4(2): 119-135. http://doi.org/10.1177/1534582305281086

Karlson, Peter y Martin Lüscher. 1959. "“Pheromones": a New Term for a Class of Biologically Active Substances». Nature 183: 55-56. 
Kovács, Krisztina J. 1998. «c-Fos as a transcription factor: A stressful (re)view from a functional map». Neurochemistry International 33(4): 287-297. http://doi.org/10.1016/S0197-0186(98)00023-0

Martín-Sánchez, Ana. 2016. Characterization of maternal behaviours in mice. Pheromonal control and nonapeptidergic substrate. Valencia: Universitat de Valencia.

Martín-Sánchez, Ana, Lynn McLean, Robert J. Beynon, Jane L. Hurst, Guillermo Ayala, Enrique Lanuza y Fernando Martínez-García. 2015. «From sexual attraction to maternal aggression: When pheromones change their behavioural significance». Hormones and Behavior 68: 65-76. http://doi.org/10.1016/j.yhbeh.2014.08.007

Nakahara, Thiago S., Leonardo M. Cardozo, Ximena Ibarra-Soria, Andrew D. Bard, Vinicius Miessler de Andrade Carvalho, Guilherme Z. Trintinalia, Darren Logan y Fabio Papes. 2016. "Detection of pup odors by non-canonical adult vomeronasal neurons expressing an odorant receptor gene is influenced by sex and parenting status». BMC Biology 14(1). http://doi.org/10.1186/s12915-0160234-9

Navarro-Hernández, Jaime, Roberto Aarón Ramírez-Ojeda y Carlos Villagrán-Vélez. 2012. Manual de procedimientos recomendables para la investigación con animales (vol. XXXIII). Mexico: Samsara.

Newman, Sarah Winans. 1999. "The medial extended amygdala in male reproductive behavior». Ann NY Acad Sci 877: 242-257. http://doi.org/10.1111/j.17496632.1999.tb09271.x

Numan, Michael y Thomas R. Insel. 2003. The Neurobiology of Parental Behaviour. New York: Springer.

Salais-López, Hugo, Enrique Lanuza, Carmen Agustín-Pavón y Fernando MartínezGarcía. 2017. «Tuning the brain for motherhood: prolactin-like central signalling in virgin, pregnant, and lactating female mice». Brain Structure and Function 222(2): 895-921. http://doi.org/10.1007/s00429-016-1254-5

Tachikawa, Kashiko S., Yoshihiro Yoshihara y Kumi O. Kuroda. 2013. «Behavioral transition from attack to parenting in male mice: A crucial role of the vomeronasal system». Annals of Internal Medicine 158(6): 5120-5126. http://doi.org/10.1523/JNEUROSCI.2364-12.2013

Wang, Zhenshan y Daniel R. Storm. 2011. "Maternal behavior is impaired in female mice lacking type 3 adenylyl cyclase». Neuropsychopharmacology 36(4): 772781. http://doi.org/10.1038/npp.2010.211 